05.3;06.5;08.2;09.1

\title{
Фемтосекундный лазерный отжиг многослойных тонкопленочных структур на основе аморфных германия и кремния
}

\author{
() А.В. Колчин ${ }^{1}$, Д.В. Шулейко ${ }^{1}$, А.В. Павликов ${ }^{1,2}$, С.В. Заботнов ${ }^{1,2}$, Л.А. Головань ${ }^{1}$, Д.Е. Преснов ${ }^{1,3,4}$, \\ В.А. Володин ${ }^{5,6}$, Г.К. Кривякин ${ }^{5,6}$, А.А. Попов ${ }^{7}$, П.К. Кашкаров ${ }^{1,2}$ \\ ${ }^{1}$ Московский государственный университет им. М.В. Ломоносова, Москва, Россия \\ ${ }^{2}$ Национальный исследовательский центр „Курчатовский институт“, Москва, Россия \\ ${ }^{3}$ Научно-исследовательский институт ядерной фризики им. Д.В. Скобельцына Московского государственного \\ университета им. М.В. Ломоносова, Москва, Россия \\ ${ }^{4}$ Центр квантовых технологий Московского государственного университета им. М.В. Ломоносова, Москва, Россия \\ ${ }^{5}$ Институт фризики полупроводников им. А.В. Ржанова СО РАН, Новосибирск, Россия \\ ${ }^{6}$ Новосибирский государственный университет, Новосибирск, Россия \\ ${ }^{7}$ Ярославский филиал Физико-технологического института им. К.А. Валиева РАН, Ярославль, Россия \\ E-mail: avkolchin@physics.msu.ru
}

Поступило в Редакцию 9 января 2020г.

В окончательной редакции 16 марта 2020 г.

Принято к публикации 16 марта 2020г.

\begin{abstract}
Исследованы процессы фемтосекунднго лазерного отжига тонкопленочных многослойных структур на основе аморфных кремния и германия, изготовленных методом плазмохимического осаждения на стеклянную подложку. Методом растровой электронной микроскопии обнаружено формирование периодических структур на поверхности облученных пленок. Анализ спектров комбинационного рассеяния света показал, что в результате воздействия фемтосекундными лазерными импульсами происходит кристаллизация аморфного германия, а также зависящее от плотности энергии импульсов смешивание германиевых и кремниевых слоев при отсутствии кристаллизации слоев аморфного кремния.
\end{abstract}

Ключевые слова: импульсный лазерный отжиг, тонкопленочные кремниевые и германиевые структуры, растровая электронная микроскопия, комбинационное рассеяние света.

DOI: 10.21883/PJTF.2020.11.49499.18201

Импульсный лазерный отжиг (ИЛО) является эффективным способом модификации аморфных полупроводников [1], в том числе тонких пленок аморфных гидрированных кремния $(a-\mathrm{Si}: \mathrm{H})[2]$ и германия $(a-\mathrm{Ge}: \mathrm{H})[3]$, поскольку в результате подобного воздействия формируются кристаллические включения в аморфной матрице, обусловливающие эффективные поглощение света и транспорт носителей заряда. В настоящее время актуальной задачей представляется поиск режимов ИЛО многослойных тонкопленочных структур $a-\mathrm{Si}: \mathrm{H} / a-\mathrm{Ge}: \mathrm{H}$, при котором происходит кристаллизация только германиевых слоев. Такой подход позволяет увеличить эффективность фотодетекторов и солнечных элементов на основе $a$-Si:H в ближнем инфракрасном диапазоне [4]. Поскольку последний материал является практически прозрачным в интервале длин волн $1.1-1.7 \mu \mathrm{m}$, наличие включений кристаллического германия $(c-\mathrm{Ge})$ в аморфной матрице приводит к увеличению оптического поглощения в этой спектральной области [5]. Ранее был продемонстрирован наносекундный ИЛО многослойных структур $a-\mathrm{Si}: \mathrm{H} / a-\mathrm{Ge}: \mathrm{H}$ [6], в результате которого наблюдались кристаллизация $a-\mathrm{Ge}: \mathrm{H}$ и смешивание слоев кремния и германия, приводящее к образованию их твердого раствора. Этот эффект является нежелательным из-за крайне малого сечения поглощения фотонов в таком материале. Поэтому более перспективным представляется использование режимов фемтосекундного ИЛО, отличающегося тем, что взаимодействие излучения с веществом и процессы термической диффузии происходят на различных временны́х шкалах. Также в результате взаимодействия лазерных импульсов с возбуждаемыми ими модами плазмон-поляритонов на поверхностях полупроводников возможно формирование лазерно-индуцированных поверхностных периодических структур (ППС) [1]. Анизотропия формы, возникающая в результате формирования периодического рельефа на поверхности облученного образца, может быть использована как для создания элементов двулучепреломляющей оптики, так и для оптической записи информации [7]. Тем не менее, насколько нам известно, исследований на эту тему применительно к структурам типа $a-\mathrm{Si}: \mathrm{H} / a-\mathrm{Ge}: \mathrm{H}$ до сих пор не проводилось.

В настоящей работе поставлена задача определить при фемтосекундном ИЛО многослойных структур $a$-Si:H/a-Ge:H оптимальную плотность энергии лазерных импульсов, при которой минимальна фракция формируемого твердого раствора $\mathrm{Ge}-\mathrm{Si}$, а также происходит образование ППС.

Исходные образцы были изготовлены на стеклянных подложках методом плазмохимического осаждения из газовой фазы. При синтезе пленок $a-\mathrm{Ge}: \mathrm{H}$ и $a-\mathrm{Si}: \mathrm{H}$ использовались газы моногерман $\left(\mathrm{GeH}_{4}\right)$ и моносилан 


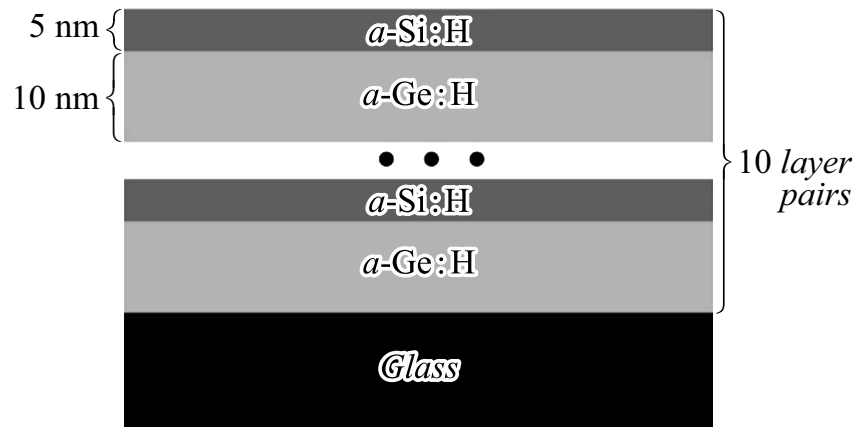

Рис. 1. Схематическое изображение многослойных тонкопленочных структур $a$-Si:H/a-Ge:H.

$\left(\mathrm{SiH}_{4}\right)$. Осаждение производилось в плазменном разряде с частотой $55 \mathrm{kHz}$. Скорость роста пленок составила $0.22 \mathrm{~nm} / \mathrm{s}$. В результате была сформирована структура из десяти пар слоев $a-\mathrm{Ge}: \mathrm{H}$ и $a-\mathrm{Si}: \mathrm{H}$ с толщинами 10 и $5 \mathrm{~nm}$ соответственно (рис. 1).

ИЛО осуществлялся с помощью лазерной системы на основе кристалла хром-форстерита $(1250 \mathrm{~nm}, 150 \mathrm{fs}$, $10 \mathrm{~Hz}, 0.1-1.1 \mathrm{~J} / \mathrm{cm}^{2}$ ) в сканирующем режиме. Лазерное излучение с данной длиной волны практически не поглощается в $a-\mathrm{Si}: \mathrm{H}$, но эффективно поглощается в $a-\mathrm{Ge}: \mathrm{H}$, что способствует эффективной кристаллизации слоев германия с минимальной модификацией кремниевых слоев в облучаемой структуре. Во время обработки образец перемещался в плоскости, ортогональной лазерному пучку, в заданном направлении со скоростью $50 \mu \mathrm{m} / \mathrm{s}$. Излучение фокусировалось на образец с помощью линзы с фокусным расстоянием $80 \mathrm{~mm}$.

Структурные свойства многослойных структур до и после облучения были исследованы с помощью растрового электронного микроскопа (РЭМ) Carl Zeiss Supra 40 и спектрометра комбинационного рассеяния света (КРC) Horiba Jobin Yvon HR800, в котором для возбуждения использовались непрерывные лазеры $\mathrm{He}-\mathrm{Ne}(633 \mathrm{~nm}, 10 \mathrm{~mW})$ и $\mathrm{Ar}^{+}(488 \mathrm{~nm}, 10 \mathrm{~mW})$. Для минимизации влияния нагрева на спектры КРС мощность возбуждающего излучения регулировалась оптическими фильтрами.

В результате воздействия фемтосекундными лазерными импульсами на исследуемой структуре формируются ППС с периодом $270 \pm 80 \mathrm{~nm}$ и ориентацией, сонаправленной с поляризацией воздействующего излучения (рис. 2), а также частицы с диаметром 100-200 nm. Образование таких одномерных решеток, вероятнее всего, вызвано интерференцией падающего излучения и возбужденных плазмон-поляритонов, обусловливающей модулированную абляцию поверхности. Генерация поверхностных электромагнитных волн вызвана фотоиндуцированной генерацией свободных носителей заряда [8], их концентрация во время действия импульса превышает порог металлизации, составляющий $8.2 \cdot 10^{21} \mathrm{~cm}^{-3}[7]$.
Важно отметить, что при описанном плазмон-поляритонном механизме оказывается возможным формирование поверхностных одномерных решеток с периодом, существенно меньшим длины волны структурирующего излучения, за счет генерации поверхностных электромагнитных волн с соответствующими величинами волновых векторов, определяемыми значениями комплексной диэлектрической проницаемости поверхности непосредственно во время облучения [1]. В то же время наличие на облученной поверхности наночастиц, скорее всего, связано с осаждением продуктов абляции [9].

В спектрах КРС необлученных образцов при длине волны возбуждения $633 \mathrm{~nm}$ (рис. 3,a) наблюдается широкая полоса от 200 до $320 \mathrm{~cm}^{-1}$ с максимумом вблизи $275 \mathrm{~cm}^{-1}$, что подтверждает аморфную структуру исходных германиевых слоев [10]. При этом, как видно из рис. 3, a, в результате ИЛО многослойной структуры произошла полная кристаллизация слоев $a-\mathrm{Ge}: \mathrm{H}$, о чем свидетельствует трансформация полосы $200-320 \mathrm{~cm}^{-1}$ в линию около $295 \mathrm{~cm}^{-1}$. Вероятнее всего, формируемая германиевая структура является кристаллической: наблюдаемое различие с характерной для $c$-Ge линией $300 \mathrm{~cm}^{-1}$ может быть объяснено либо проявлением дисперсии фононов из-за возникновения в результате облучения нанокристаллов германия $(n c-\mathrm{Ge})$ размером менее $10 \mathrm{~nm}$, либо наличием механических напряжений в германиевых слоях [6].

Похожие изменения фазового состава обнаружены и при использовании длины волны возбуждения $488 \mathrm{~nm}$ (рис. $3, b)$. Однако в данном случае также удалось подтвердить аморфную структуру кремниевых слоев в исходных и облученных областях образцов, о чем свидетельствует широкая полоса в области от 440 до $510 \mathrm{~cm}^{-1}$ с максимумом вблизи $480 \mathrm{~cm}^{-1}$ [10]. Интенсивность пика $a$-Si:H при возбуждении лазером с длиной волны $633 \mathrm{~nm}$ (рис. 3,a) значительно меньше, чем при возбуждении с длиной волны $488 \mathrm{~nm}$ (рис. $3, b$ ). Это может быть объяснено бо́льшими изменениями ко-

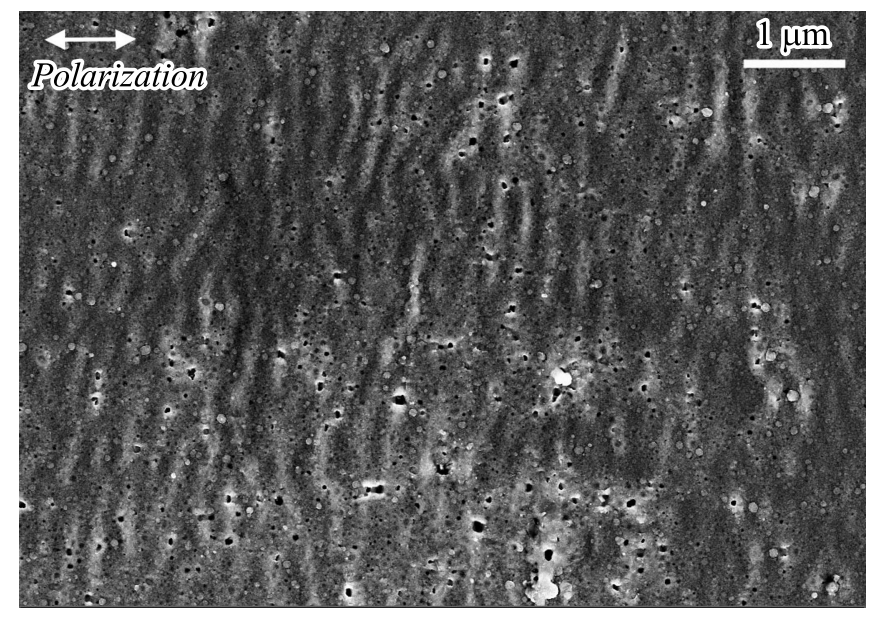

Рис. 2. РЭМ-изображение подвергшейся ИЛО области на поверхности многослойной структуры $a-\mathrm{Si}: \mathrm{H} / a-\mathrm{Ge}: \mathrm{H}$. 

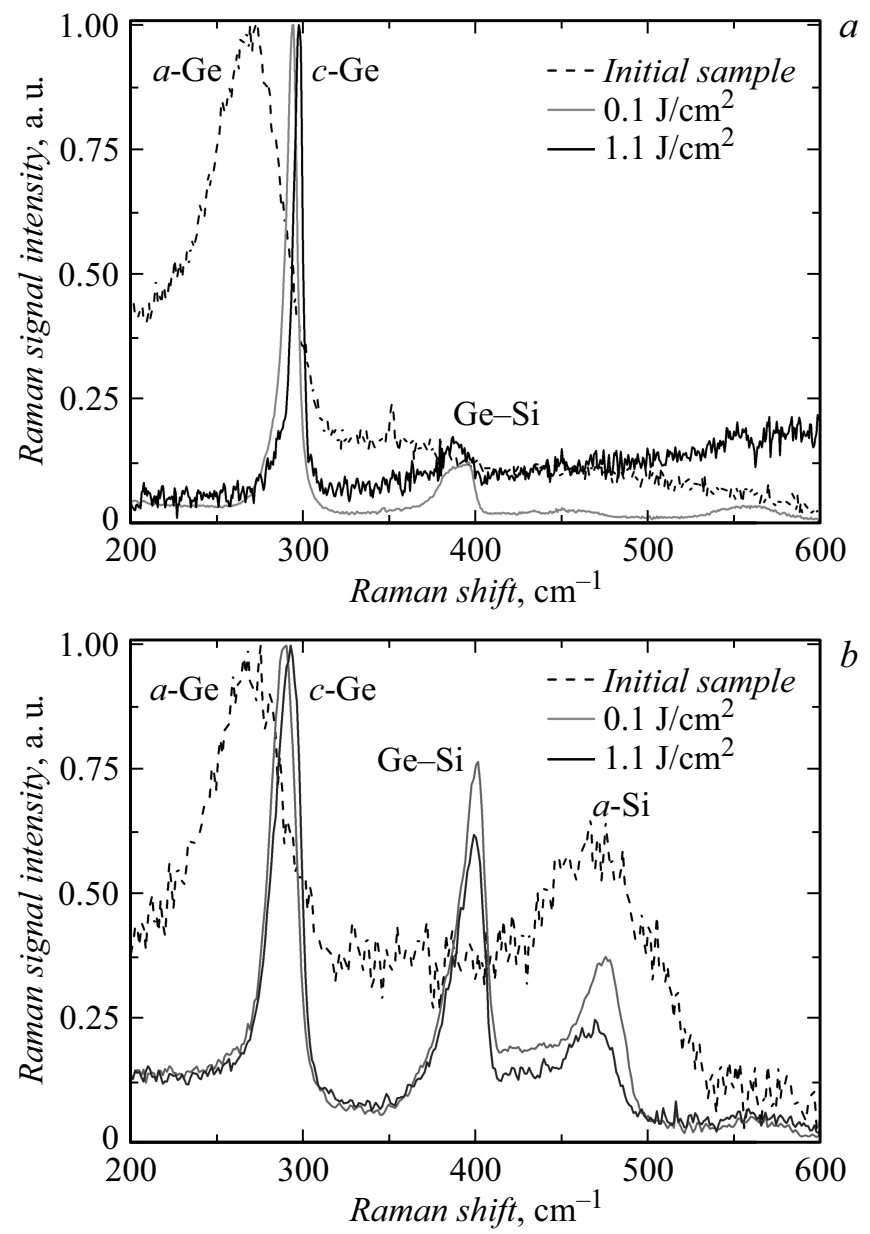

Рис. 3. Спектры КРС исходного образца $a-\mathrm{Si}: \mathrm{H} / a-\mathrm{Ge}: \mathrm{H}$, а также облученных областей при различных плотностях энергии лазерных импульсов для длин волн возбуждения $633(a)$ и $488 \mathrm{~nm}(b)$.

эффициента поглощения для слоя $a-\mathrm{Si}: \mathrm{H}$, чем для слоя $a-\mathrm{Ge}: \mathrm{H}$, при уменьшении длины волны излучения [11].

Следует также отметить возникновение в спектрах КРС после ИЛО полосы $370-425 \mathrm{~cm}^{-1}$, соответствующей твердому раствору $\mathrm{Ge}-\mathrm{Si}$ [12]. Интенсивность данной полосы зависит от стехиометрического параметра $x$ в твердом растворе $\mathrm{Ge}_{x} \mathrm{Si}_{1-x}$, который определяется по формуле

$$
x=\frac{2 I_{\mathrm{Ge}} / I_{\mathrm{Ge}-\mathrm{Si}}}{B+2 I_{\mathrm{Ge}} / I_{\mathrm{Ge}-\mathrm{Si}}},
$$

где $I_{\mathrm{Ge}}$ и $I_{\mathrm{Ge}-\mathrm{Si}}$ - интенсивности линий $c$-Ge и $\mathrm{Ge}-\mathrm{Si}$ соответственно, $B$ - параметр, который, согласно ранее полученным данным [12], близок к 2. С увеличением плотности энергии лазерных импульсов наблюдаются уменьшение значения $I_{\mathrm{Ge}-\mathrm{Si}}$ и, следовательно, рост значения стехиометрического параметра $x$ от 0.5 до 0.7 .

Изменения фазового состава в результате воздействия фемтосекундного лазерного излучения могут быть объяснены эффективным поглощением света слоями $a-\mathrm{Ge}: \mathrm{H}$ и практически полным его отсутствием в слоях
$a-\mathrm{Si}: \mathrm{H}$ в диапазоне длин волн $1.1-1.7 \mu \mathrm{m}$. Коэффициенты поглощения света $a-\mathrm{Ge}: \mathrm{H}$ и $a-\mathrm{Si}: \mathrm{H}$ для длины волны $1250 \mathrm{~nm}$ составляют около 16000 [13] и $10 \mathrm{~cm}^{-1}$ [14] соответственно, а следовательно, увеличение интенсивности ИЛО на длине волны $1250 \mathrm{~nm}$ может привести как к абляции $a-\mathrm{Ge}: \mathrm{H}$, так и к недостаточному нагреву слоя $a$-Si:H из-за низкого коэффициента поглощения, что не вызывает впоследствии роста сигнала КРС от твердого раствора $\mathrm{Ge}-\mathrm{Si}$. Ранее в работе [6] при наносекундном ИЛО на длине волны излучения $694 \mathrm{~nm}$ были зафиксированы кристаллизация слоев $a-\mathrm{Ge}: \mathrm{H}$ и отсутствие фазовых изменений в слоях $a$-Si:H, а также увеличение интенсивности сигнала КРС от твердого раствора $\mathrm{Ge}-\mathrm{Si}$ с ростом плотности энергии лазерных импульсов. Это отличие можно объяснить тем, что для длины волны $694 \mathrm{~nm}$ коэффициенты поглощения $a-\mathrm{Ge}: \mathrm{H}$ и $a-\mathrm{Si}: \mathrm{H}$ составляют 88000 [12] и $47400 \mathrm{~cm}^{-1}$ [13], что, напротив, может привести к значительному нагреву слоев с последующим их смешиванием.

Таким образом, проведенные исследования показывают формирование поверхностных структур с периодом $270 \pm 80 \mathrm{~nm}$ и ориентацией, перпендикулярной поляризации воздействующего излучения, в результате фемтосекундного ИЛО многослойных структур $a-\mathrm{Si}: \mathrm{H} / a-\mathrm{Ge}: \mathrm{H}$ при длине волны $1250 \mathrm{~nm}$ и плотности энергии лазерных импульсов от 0.1 до $1.1 \mathrm{~J} / \mathrm{cm}^{2}$. В облученных областях обнаружены практически полная кристаллизация слоев $a$-Ge:H при отсутствии кристаллизации слоев $a-\mathrm{Si}: \mathrm{H}$, а также возникновение твердого раствора $\mathrm{Ge}-\mathrm{Si}$. Однако в отличие от наносекундного ИЛО при длине волны излучения $694 \mathrm{~nm} \mathrm{c} \mathrm{ростом}$ плотности энергии лазерных импульсов происходит уменьшение доли твердого раствора Ge-Si. Данные различия могут быть объяснены применением длины волны излучения $1250 \mathrm{~nm}$ при фемтосекундном ИЛО многослойных структур $a-\mathrm{Si}: \mathrm{H} / a-\mathrm{Ge}: \mathrm{H}$, для которой $a$-Si:H является практически прозрачной, в то время как $a$-Ge:H демонстрирует сильное поглощение для излучения с такой длиной волны.

\section{Финансирование работы}

Работа выполнена при поддержке программы фундаментальных исследований ЯФ ФТИ РАН № 0066-20190003 .

\section{Конфликт интересов}

Авторы заявляют, что у них нет конфликта интересов.

\section{Список литературы}

[1] Либенсон М.Н., Яковлев Е.Б., Шандыбина Г.Д. Взаимодействие лазерного излучения с веществом. СПб.: НИУ ИТМО, 2014. $181 \mathrm{c}$.

[2] Амасев Д.В., Хенкин M.B., Drevinskas R., Kazansky P., Казанский А.Г. // ЖТФ. 2017. Т. 87. В. 6. С. 909-913. 
[3] Макин В.С., Пестов Ю.И., Макин Р.С. // Оптика и спектроскопия. 2017. Т. 123. В. 2. С. 264-268.

[4] Кривякин Г.К., Володин В.А., Шкляев А.А., Mortet V., More-Chevalier J., Ashcheulov P., Remes Z., Stuchlikova T.H., Stuchlik J. // ФТП. 2017. Т. 51. В. 10. C. $1420-1425$.

[5] Li C., Ni J., Sun X., Wang X., Li Z., Cai H., Li J., Zhang J. // J. Phys. D: Appl. Phys. 2017. V. 50. P. 045108.

[6] Володин В.А., Кривякин Г.К., Ивлев Г.Д., Прокопьев С.Л., Гусакова С.В., Попов А.А. // ФТП. 2019. Т. 53. В. 3. С. 423 429.

[7] Shuleiko D.V., Martyshov M.N., Presnov D.E., Zabotnov S.V., Kashkarov P.K. // J. Phys.: Conf. Ser. 2020. In press.

[8] Марциновский Г.А., Шандыбина Г.Д., Дементьева Ю.С., Дюкин Р.В., Заботнов С.В., Головань Л.А., Кашкаров П.К. // ФТП. 2009. Т. 43. В. 10. С. 1339-1345.

[9] Заботнов С.В., Ежсов А.А., Головань Л.А., Ластовкина М.А., Панов В.И., Тимошенко В.Ю., Кашкаров П.К. // ФТП. 2007. Т. 41. В. 8. С. 1017-1020.

[10] Bermejo D., Cardona M. // J. Non-Cryst. Solids. 1979. V. 32. P. 405-419.

[11] Cardona M., Merlin R. Light Scattering in Solids IX. Berlin: Springer-Verlag, 1985. $432 \mathrm{p}$.

[12] Володин В.А., Ефремов М.Д., Якимов А.И., Михалёв Г.Ю., Никифоров А.И., Двуреченский А.В. // ФТП. 2007. Т. 41. B. 8. C. 950-954.

[13] Ciesielski A., Skowronski L., Pacuski W., Szoplik T. // Mater. Sci. Semicond. Proc. 2018 V. 81 P. 64-67.

[14] Ambrosone G., Coscia U., Lettieri S., Maddalena P., Minarini C. // Mater. Sci. Eng. B. 2003. V. 101. P. 236-241. 